\title{
Work Stress, Coping Strategies and Resilience: A Study among Working Females
}

\author{
Shueh-Yi Lian ${ }^{1} \&$ Cai Lian Tam ${ }^{1}$ \\ ${ }^{1}$ School of Medicine and Health Sciences, Monash University Sunway Campus, Bandar Sunway, Selangor \\ Darul Ehsan, Malaysia \\ Correspondence: Cai Lian Tam, School of Medicine and Health Sciences, Monash University Sunway Campus, \\ Bandar Sunway, Selangor Darul Ehsan, Malaysia. Tel: 60-3-5514-4974.E-mail: tam.cai.lian@monash.edu
}

\author{
Received: March 11, 2014 Accepted: April 16, 2014 Online Published: May 26, 2014 \\ doi:10.5539/ass.v10n12p41 URL: http://dx.doi.org/10.5539/ass.v10n12p41
}

\begin{abstract}
The aim of this review was to evaluate research relating to the effects of coping strategies and resilience on the level of workplace stress. Much of the research focused on working mothers and working females in general. It was found that working females experienced more work stress as compared to men. And currently in Malaysia, social policies that support working females, especially working mothers, has not been adopted fully by most corporations. Furthermore, the evidence for effective problem-focused and emotion-focused coping was inconsistent. It was concluded that correlation between work stressors and the adopted coping strategies may vary depending on the type of problems being dealt with and the interplay between the employee and the demand. Moreover, resilience literature revealed this concept as an enhancement of an individual's adaptability and survival in the presence of occupational stressors and success in overcoming the stressors results in increased resilience to future hardships. This article identifies a number of research gaps for advancing work stress research, in particular: 1) limited work stress research on Malaysian working women and mothers, and; 2) limited literature on relating resilience to coping strategies and work stress.
\end{abstract}

Keywords: avoidance coping, coping strategies, emotion-focused, problem-focused, resilience, working females, working mothers, work stress

\section{Overview}

Throughout the past few decades in Malaysia, the achievement of gender equality and women rights has opened various opportunities for women to participate in male-dominated fields such as managerial and executive positions. With the driving forces of rapid economic growth due to the implementation of the New Economic Policy (NEP) by the government in 1969 (Noor, 1999) and greater opportunities for female education, the gender gaps in the labour force have been reducing with the increasing female participation in paid work. Due to these employment opportunities, the women's role has undergone some changes. Research interests relating to employed females sparked in the 1980s and 1990s when labour force growth was considerably higher for females than for men in most countries (Lim, 2009). Extensively investigated areas within the realm of working females include work-family conflict and dual-role stress in working mothers (e.g., Ahmad, 1996; Leader, 1987; McLaughlin, Cormier, \& Cormier, 1988; Wanamaker \& Bird, 1990), personality characteristics that influence perceived work stress (e.g., Baltes, Zhdanova, \& Clark, 2011; George, Helson, \& John, 2011), and perceived stress in single working mothers (e.g., Broussard, Joseph, \& Thompson, 2012; Monroe, 1991).

Research that focused on interventions and stress management programmes for working females, especially working mothers (e.g., Harlin-Clifton, 2008; Kline \& Snow, 1994) examined gender differences in work stress and coping (e.g., Shek, 1989), the well-being of working females (e.g., Kushnir \& Melamed, 2006; Noor, 1999; O’Neill \& Zeichner, 1985; Raak \& Wahren, 2005; Sandmark \& Renstig, 2010) as well as psychological characteristics that influence the regulation of work stress in working females (e.g., Klainin, 2009; Snow, Swan, Raghavan, Connell, \& Klein, 2003).

This paper aims to review the current state of knowledge with respect to the psychological components that have demonstrated to influence the level of work stress in working females, namely resilience and coping strategies. Specifically, literature on working mothers and the general working female population will be reviewed. This paper commences with statistics on the working female population in Malaysia followed by a review of the 
literature related to the constructs of work stress, coping strategies and resilience. Prior studies investigating work stress, coping strategies and resilience elements in working mothers and the general working female population will be reviewed thereafter. Lastly, the review will conclude with the research gaps and suggestions for further research.

\section{Statistics on Malaysia's Working Female Population}

According to The World Bank data (2013), Malaysia's female labour participation rate reached a plateau of 44\% of the female population above ages 15 in recent years. The survey "Women of Tomorrow-A Study of Women around the World" was carried out in 21 countries in 2011. Malaysian women ranked $16^{\text {th }}$ as the most stressed out (Holdings, 2011). In 2011, 67.6\% of the total female population in Malaysia was aged 15 to 64 and $47.9 \%$ were in the labour force (Ministry of Women, Family and Community Development [MWFCD], 2012). It is also interesting to note the mean age at first marriage for females increased from 23.5 years in 1980 to 25.7 years in 2010 (MWFCD, 2012). Unlike the pre-colonial days where Malaysian women were usually given into marriage at an early age, greater educational and job opportunities have brought about changes in their social roles (Kok, 1982; von Elm \& Hirschman, 1979). Women since then have increased autonomy in making decisions relating to marriage and in furthering their career and education horizons (Kok, 1982; von Elm \& Hirschman, 1979). As Lim (2009) noted, the fertility rate for Malaysia has slowed down to 3.3 children per woman despite the rapid socio-economic advancement and increased female labour participation rates. With this in mind, the current marriage trends (late marriages) as well as the rising living cost in Malaysia (Chong, 2014) may play an interactive role with work stress whilst contributing to the decreasing fertility rate in Malaysia.

\section{What Is Stress?}

\subsection{Definition of Stress}

The word 'stress' is not unfamiliar to most people. The causes of stress can be environmental, social, biological or psychological factors that challenge an individual to change or adapt (Bourne \& Yaroush, 2003). For instance, environmental and social factors include the environment of a workplace and relationships with others whereas biological and psychological factors encompass the nutritional status, emotional wellbeing and overall health levels of an individual (Gazzaniga, Heatherton, \& Halpern, 2010).

In the psychological view, stress is generally used to describe a response to demands that is greater than an individual's ability to cope, which disrupts the individual's physical or mental equilibrium and poses a threat to the individual's general well-being (Lazarus \& Folkman, 1984). The body's reaction to stress involves psychological and physical arousal has been described abundantly in literature on its contribution in physical and mental health impairments (Melchior et al., 2007). Lazarus and Folkman (1984) suggested that for a situation to elicit a stress response, the situation has to be appraised by the individual as stressful, that is, the demands on the individual's resources exceeds his or her ability.

Similar to the psychological view of stress, the sociological view focuses on the three fundamental concepts of the stress process, that is, the causes of stress (stressors), the coping resources (mediators and moderators) and the outcome of stress that varies across different social conditions (Pearlin, 1989). This alternative view will be reviewed further below.

\subsection{Theoretical Frameworks of Stress}

One famous stress response called the "fight or flight" response was first developed to explain our bodily reaction to stress. The "fight or flight" response is our body's sympathetic nervous system reacting to a stressful event by producing endocrine hormones such as adrenaline and cortisol to heighten our response towards a perceived threat or challenge (Gazzaniga et al., 2010). The body's responses include increased heart rate and blood pressure, increased skeletal muscle tension, and alertness (Gazzaniga et al., 2010). The arousal enables the body to prepare for the right course of action-to fight or to flee.

Also, Dr. Hans Selye, a major researcher on stress response proposed the General Adaptation Syndrome (GAS) to explain stress reactivity (Gazzaniga et al., 2010). There are three phases in the GAS-the alarm stage, resistance stage and exhaustion stage. The alarm stage is similar to the "fight or flight" response such that the endocrine system is activated when the body confronts a stressor. When the stress is ongoing, the body goes into the resistance stage whereby the body attempts to maintain equilibrium whilst adapting to the stress. If the stress persists and turns chronic, the adaptive mechanisms will start to deplete and the body enters the exhaustion stage. At the exhaustion stage, the bodily reactions to stress are experienced at a greater intensity leading to increased susceptibility to fatigue related illnesses and disorders (Gazzaniga et al., 2010). Nonetheless, the above theories have been criticized for not taking into account non-major events and self-perception that might also impact 
stress (O'Bryan, 2008).

Unlike other stress research that has been done in the fields of physiology and medicine, Pearlin (1989) spearheaded the discussion of stress in the sociological view with the main focus of stress directed to the social distribution of mental health and wellbeing. Pearlin (1989) emphasized that comprehensive analysis of the structural arrangements of people's lives that involve their social structure and inner functioning is warranted. For the sake of clarification, the social structures mentioned above comprise of the diverse social systems of stratification in society and institutions, such as social and economic status, gender, occupational roles and statuses (Pearlin, 1989).

As mentioned previously, the basic concepts of the stress process involves the stressors, coping resources and stress outcomes. The sociological theory of stress views stress as an interaction of an individual's position in the social organisation that exposes them to various stressors, which in turn give rise to stress outcomes (Pearlin, 1989). It looks into the problems rooted in social roles that often endure in an individual's relationships, experiences and wellbeing causing role strain. The theory also takes into account the convergent effects of significant life events and daily life hassles that reflect important life experiences that are sometimes stressful. Thus, the theory proposes to examine stressful experiences as a whole, in combination of various groups of stressors in the organization of lives and structure of experience to effectively analyse and pinpoint the stressors that causes durable strains.

The transactional model of stress and coping (TMS) contend that stress is subjective where individuals experience the same stressor differently (Lazarus \& Folkman, 1984). This varied reaction to the same stressful event suggests that there is a transaction between individuals and their environment and a critical factor that influences the interpretation of the stressful event is the way it is appraised (Glanz, Rimer, \& Lewis, 2002; Lazarus \& Folkman, 1984). Hence, the precipitation of negative health outcomes is not only caused by stress but also the appraisal of the situation and effectiveness of the adopted coping strategies (Lazarus \& Folkman, 1984). As Lazarus and Folkman (1984) noted, stress is part of human daily living and to be able to cope with stress makes a difference in adaptation outcome.

In relating Pearlin's (1989) sociological theory of stress with Lazarus and Folkman's (1984) TMS, similarities between the two can be observed in terms their fundamental concepts of stress-stressful events, coping strategies or resources and the stress outcomes. However, the appraisal of a stressful event is an important aspect of understanding stress is considered in the TMS and as this literature review attempts to take a holistic approach, the TMS was chosen for this review in looking at perceived stress.

Within the TMS, stress is identified as the outcome of imbalance between demands and resources, and ranges from daily hassles to major life events (Lazarus \& Folkman, 1984). Mothers with dependent children who are also working have a variety of demands and resources, and may perceive potential imbalance differently. This model is more relevant to the working mother and the general working female population than the other stress theories previously highlighted as it has an integrative nature that can better capture the essence of the working mother and working female population. Furthermore, the interplay between the different coping strategies will surface as they relate to women's stress. Thus, the process of appraisal, behavioural outcome and stress is continuous and managing stress can result from using different coping strategies to appraise or respond to the stressor (Michie, 2002).

\subsection{Stress and Mothers}

As noted earlier, the widespread entry of females into the labour force is a characteristic of the past decades. Females are increasingly entering the workforce to contribute financially to the family survival (Lim, 2009). They are not only entering the work force in greater numbers but also remaining in the work force throughout their child-bearing and child-rearing years (Lim, 2009). Even with the changing societal trends and expectations, it is still 'expected' that working females should assume the traditional role of a homemaker (Noor, 1999; Nair, 2011). The added elements of motherhood in some working females increased the possibility of acute dual-role or multiple role stress as a mother, employee and spouse or partner (Kline \& Snow, 1994; McLaughlin et al., 1988; Meleis \& Stevens, 1992; O’Neill \& Zeichner, 1985; Snow et al., 2003). Noor's (1999) preliminary findings on Malaysian working women's roles and wellbeing showed that the juggle between work and family demands have contributed to the adverse psychological and emotional wellbeing for the working mothers, this includes feelings of guilt, anxiety or decreased role satisfaction at work and home. Killien and Brown (1987) summarized that when demands from work and family roles opposes each other, the mother is likely to suffer stress and negative health consequences. Therefore, understanding the influence of women's stress and role conflict on their health warrants consideration of the critical contribution of individual characteristics, such as 
cognitive processing, coping skills and resiliency.

The interest in studying stress and coping in working mothers started as researchers were concerned with the correlation between maternal and child well-being as it has been shown to predict quality maternal-child interactions (Bynum, Smith, \& Brody, 2005; Ritchie, 1982). Canam (1986) found that working mothers with pre-school children found it difficult to shut work 'off' when at home. Canam (1986) further discovered that work deadlines were the most frequently mentioned stressor and interfered with the family environment. On the contrary, Ritchie's (1982) findings indicated that even though working mothers found it more stressful than full-time mothers in caring for their children, working mothers were rated warmer, more confident and less anxious than full-time mothers. The mother-child relationship among working mothers were likely to be positively evaluated as well when compared to full-time mothers (Ritchie, 1982).

\subsection{Work Stress in the Working Female Population}

Stress in the workplace poses a major problem for both the organization and employees as it negatively affects the employees' general well-being and work performance, and incurs costs on the organization (National Institute for Occupational Health and Safety [NIOSH], 1999; Spangler, Koesten, Fox, \& Radel, 2012). Work stress can be defined as the negative effects on the worker's physical and emotional health as a result of the mismatch between the worker's capabilities, resources or needs and the requirements of the job (NIOSH, 1999). The changing and modernization of the current working environment have had employees work longer hours, adapt effectively to change, task complexity and demands for greater technical skills (Snow et al., 2003). In other words, the world is moving faster than it used to be. As employees engage more time in their work, work stressors are also increasing the risk of adversely affecting the employees' psychological and physical well-being (Snow et al., 2003). Based on the transactional model of stress and coping (Lazarus \& Folkman, 1984), how employees cope and adapt to these demands may serve to lower or increase the risk for negative health outcomes.

Sources of work stress such as work overload, job insecurity, work interpersonal relationships, role conflict, commuting stress etc. have been identified to play a primary role in employee's health and are somewhat similar for both males and females (Days \& Livingstone, 2001). Frequent absenteeism, mood disorders, tardiness and intentions to quit are usually predictors of stressful working conditions (Sandmark \& Renstig, 2010). Generally, work stressors can have an effect on all employees, but may have unique consequences for females who are often in lower paid jobs with less status and control (Snow et al., 2003). Furthermore, work stressors unique to working females also include sexual harassment, lower chances of career advancement and sexual inequality, may negatively impact females (Street, Gradus, Stafford, \& Kelly, 2007). Street et al. (2007) highlighted that sexual harassment in the workforce is more likely to happen to single females in their twenties. In contrast to that, Wee et al. (n. d.) reported findings on 63 Malaysian females in male-dominated managerial roles that stress related to sexual harassment was moderate; instead, prejudice was a more significant work stressor. The female sample reported that they were subjected to prejudiced attitude by both male and female colleagues which resonates with Nair's (2005) findings that females with higher authority are extra critically evaluated even when their work capability and competence matches or exceed those of the male colleagues. This workplace incivility has shown to be a predictor of psychological distress (Lim, Cortina, \& Magley, 2008).

Furthermore, a longitudinal study by Melchior et al. (2007) assessed 891 participants (45.6\% female) at the age of 32 found that participants exposed to high job demands experienced a double risk of major depressive disorder (MDD) and generalized anxiety disorder (GAD). Melchior et al. (2007) controlled for any pre-existing disorders in the participants prior entry into the workforce and predicted that $45 \%$ early onset of MDD and GAD were attributable to work stress. Similarly, Snow et al. (2003) also found work stress as a significant contribution factor to the increase of negative psychological symptoms in 239 females employed in secretarial positions in the USA.

Sandmark and Restig (2010) interviewed 16 females chosen from a cohort of 300 females that held full-time white-collar jobs in high level positions usually dominated by men. Their study was interested in the long-term sick leave in female white-collar workers that resulted from burnout and stress-related illnesses. The findings were consistent with numerous studies such that results showed that females with work stress experienced inequality, higher expectations than their male counterparts, mismatch between competence and job demands. The imbalance in work and private life contributed to the exposure of long term external and internal stress that manifested as overexertion. In the attempt to maintain their work performance and expected responsibilities as a wife, mother or partner, the working females had little time for themselves in terms of recuperation due to long working hours and commitment to work (Sandmark \& Restig, 2010). 
In addition, commuting stress plays a major part in Malaysia as the country grows economically. The increased size of the working class and the growth of suburbs have created a growing trend of people who work further away from home thus increasing commuting time from one end to the other (Mohd Mahudin, 2012). Furthermore, there is also a rise in automobile use making it the primary transportation in Malaysia and this has contributed to increased road congestions as well (Mohd Mahudin, 2012). Studies have shown that commuting experience can negatively impact an individual's health and organisational well-being (Novaco et al., 1991; Wener et al., 2005). Hence, Mohd Mahudin (2012) investigation on the effects of commuting on organisational wellbeing among Malaysians in the Klang Valley who travelled by train found that longer commuting time contributed to somatic symptoms such as tiredness, stiff muscles and headaches. Consistent with existing literature, these workers expressed increased intention to quit their jobs. The results also showed negative associations between commuting stress and job satisfaction (Mohd Mahudin, 2012).

Although the relationship between working female's work stress and general well-being have been consistently documented, not all female employees, mother or not, experience negative health outcomes. Therefore, it is important to understand what additional factors might explain why, or under what conditions, these employees experience the impact from work stress. The transactional model of stress and coping discusses the individual differences in cognitive appraisals and coping skills that one possesses in regards to that. The review will now look to the various functions of coping strategies.

\section{Coping Strategies}

\subsection{Definition of Coping and Coping Strategies}

Coping is essentially defined as the efforts used to manage the internal or external demands that are appraised as potentially harmful and stressful to the individual (Lazarus \& Folkman, 1984). Coping is a process and it progresses across several stages (Lazarus \& Folkman, 1984). Lazarus and Folkman (1984) defined the stages as primary and secondary appraisal. Primary appraisal is the initial decision used to assess whether an event is harmful and controllable, it is the evaluation stage. Secondary appraisal regards the perception of the abilities to cope with the stressful event; it is the managing stage. These cognitive appraisal processes facilitate the ability to predict the type of coping strategy that one will use; whether preventive measures are taken or regulation of emotional distress.

Consequently, coping strategies are behaviours adopted by the individual in response to reduce the adverse effects of the appraised stressor (Fleming, Baum, \& Singer, 1984; Lazarus \& Folkman, 1984). According to Lazarus and Folkman (1984), there are two categories of coping strategies-problem-focused coping and emotion-focused coping. Problem-focused coping actively confronts the problem and tackles the problem head-on. It is usually used when the individual appraises the situation as optimistic and controllable (Carver, Scheier, \& Weintraub, 1999). Emotion-focused coping features behaviour that reduces the emotional distress on the stressor, for instance, avoidance, minimization, selective attention and positive comparison. This coping strategy is most likely utilised when the individual perceives the situation as unavoidable and uncontrollable (Carver et al., 1999). Nevertheless, problem-focused and emotion focused coping are not two distinct functions but both facilitate and impede each other in the coping process and may be more beneficial than the other in different situations (Lazarus \& Folkman, 1984). To facilitate the coping process, seven categories of coping resources have been identified: health and energy, positive beliefs, problem solving skills, social skills, social support and material resources. In the following section, the relationship between work stress and coping strategies in working mothers and the working female population will be discussed.

\subsection{Work Stress and Coping Strategies}

Given the importance of maternal coping and mother-child interaction, Eisengart et al. (2006) explored the factor structure of coping in a sample of mothers experiencing high, but varying, levels of life stress and attempted to develop a coping model that would have clinical applicability. Their sample included mothers with 2 year old children that were born at full-term or at very low birth weight. The researchers conducted an Exploratory Factor Analysis (EFA) on the Coping Orientation to Problem Experience (COPE) Inventory and yielded a 7-factor model of coping. The results were cross-validated with Confirmatory Factor Analysis (CFA). The data revealed that avoidant and emotion-focused coping strategies were consistently correlated with higher maternal distress. Eisengart et al. (2006) suggested that providing mothers with information on active coping strategies may improve mother-child interaction and relationship. Similarly, Killien and Brown (1987) and Morris (1991) reported that almost half of the working mothers did nothing at all in response to work stress, $49 \%$ and $48 \%$ respectively. All other responses also were related to emotion-focused coping, such as seek social support, complained to co-worker and avoidance. Besides that, Killien and Brown (1987) noted that problem-focused 
coping was the second most used strategy after combining all individual coping responses into seven categories.

Although there is limited literature on mother-child relationship among working mothers in Malaysia, childcare and support policies are gradually adopted by a handful of Malaysian multi-national, public listed and government-linked corporations for working mothers. According to a recent "Retaining Women in the Workforce" 2012 survey conducted in Malaysia where 824 professional men (30.5\%) and women (69.5\%) responded. It was revealed that only $30 \%$ of Malaysian employers who participated in the survey had flexible work arrangements policy for working mothers and only $7 \%$ had childcare support facilities (Talent Corp \& ACCA, 2012). In addition, it was also reported that $60 \%$ of the respondents still perceived a lack of gender equality practices at their workplace. Furthermore, $65 \%$ and $43 \%$ of the respondents attributed the main reasons for leaving the workforce to the difficulty of attaining work-life balance and increased family commitments. The survey further highlighted that organisational support such as career development opportunities, flexible working hour, training and mentoring programmes etc. play a major role in supporting the working mothers. Hence, it can be presumed from this survey that working mothers were experiencing not only work stress and little organisational support but also stress from family commitments. On another note, this survey is the latest and perhaps the first to represent the views of Malaysian working mothers in such a large scale.

Moreover, in studying the general working female population, Raak and Wahren (2005) investigated the relationship between headache and coping among 257 female employees in a Swedish university hospital. Results revealed that tension-type headache sufferers utilised more emotion-focused coping strategies to deal with work stress while headache free participants utilised problem-focused coping strategies. It was implied that individuals with stress-induced headache who used emotion-focused coping viewed the pain as uncontrollable. Likewise, Snow et al. (2003) found that greater work stressors predicted more negative psychological symptoms and increased use of problem-focus coping significantly predicted fewer symptoms. At the same time, however, high levels of work stressors also predicted increased reliance on avoidance coping (subset of emotion-focused coping) which adversely increased negative psychological symptoms (Snow et al., 2003).

However, previous research has revealed some inconsistencies regarding the relationship between work stress and problem-focused and avoidance coping. In a study on working mothers who played multiple roles as teacher and student, O'Bryan (2008) did not find a similar result for avoidance and problem-focused coping. They hypothesized that avoidance and problem-focused coping will predict perceived stress but the relationship was not significant as only emotion-focused coping had a significant negative relationship with perceived stress. Similarly, Day and Livingstone (2001) also found no relationship between problem-focused coping, work stress and psychological symptoms in working females.

With respect to the studies above, one possible explanation for the contradictions is that the correlation between work stressors and the adopted coping strategies may vary depending on the type of problems being dealt with and the interplay between the employee and the demand (Lazarus \& Folkman, 1984; Snow et al., 2003).

\section{Resilience: Personality Trait or Process?}

\subsection{Definition of Resilience}

Resilience has been defined as the capacity to withstand, regulate and cope with ongoing life challenges and succeeds in maintaining equilibrium despite negative effects from stress (DiCorcia \& Tronick, 2011; Montpetit, Bergeman, Deboeck, Tiberio, \& Boker, 2010; O'Neill \& Dias, 2007; Schetter \& Dolbier, 2011). Most studies often associate the concept of resilience with extreme or adverse stress, traumatic events or loss (DiCorcia \& Tronick, 2011; Schetter \& Dolbier, 2011) with more focus on children and adolescents and less on adults (Jackson, Firtko, \& Edenborough, 2007; Kitano \& Lewis, 2005; Wagnild \& Young, 1993). Resilience plays the important role of a protective factor, protecting the individual's psychological being and increasing positive changes when coping with stressful situations (Dolbier, Jaggars, \& Steinhardt, 2010; Kinman \& Grant, 2011). It seeks to promote and maintain health and prevent illness (Muller, 2009). Recent literature has gradually shifted focus to study resilience in the context of overcoming everyday moderate stress instead of chronic stresses like abuse and discrimination as it is also perceived as a stressor that may negatively impact an individual (DiCorcia \& Tronick, 2011; Lazarus \& Folkman, 1984).

\subsection{Psychosocial Interactive Model of Resilience}

The traditional approach to resilience is usually centered either on internal qualities such as personality traits, behavioural competence and coping skills (Bartley, Schoon, Mitchell, \& Blane, 2010) or only on external social factors such as social and psychological characteristics (Neill \& Dias, 2001). Muller (2009) challenged these schools of thoughts by introducing the psychosocial interactive model of resilience, where both the internal and 
external domains of the individual are considered in the response to stressful conditions. This model takes into account the development over the lifespan where time is a factor for resilience. It is a dynamic process and it can be learned (Neill \& Dias, 2001; Rutter, 2012; Spangler et al., 2012). As supported in many research on childhood resilience (Wagnild \& Young, 1993) resilience growth may not be in a linear fashion as it can change and develop over time-built or lost-depending on the availability of the resilience resources (Muller, 2009; Schetter \& Dolbier, 2011).

Similarly, DiCorcia and Tronick (2011) discussed resilience as "a process of regulating everyday life stressors" (p. 1593) and that individual of all backgrounds experience stressors in different ways and moderations. This idea is somewhat similar to the transactional model of stress and coping (Lazarus \& Folkman, 1984) whereby the regulation of stressors varies according to individual. The Everyday Stress Resilience Hypothesis (DiCorcia \& Tronick, 2011) states that resilience growth is dependent on the regulatory success or failure of everyday stress in an individual; the more experience and success in stress regulation, the more equipped an individual is to face greater challenges. DiCorcia and Tronick (2011) presented a well thought of analogy for the Hypothesis: Marathon runners do not run the full marathon distances for stamina training; instead they run a gradual increase of distances in each training over a period of time. The rationale behind the analogy is progressive training develops the runner's stamina. The gradual increase in capacity helps the different muscular and metabolic mechanisms to be prepared for the full distance. Analogous to resilience growth, successfully overcoming adversity or stress builds resilience and prepares one for future stress. However, maintenance training is required to prevent stamina loss, this takes into account the possibilities of resilience being built or lost. Even though DiCorcia and Tronick (2011) main focus was on infant experiences in stress regulation and resilience growth, their core argument on the Everyday Stress Resilience Hypothesis is applicable to most individuals. Nevertheless, as noted in their review, further research and empirical evidence are needed for the Hypothesis to be valid, in particular, a detailed understanding of individual experiences in self-regulation capacities.

As a response to inconsistencies in understanding resilience, Polk (1997) conducted a meta-analysis that examined 26 research papers to identify the various characteristics and themes that define resilience. She identified four patterns of resilience: dispositional pattern, which encompasses physical and ego-related psychosocial attributes; relational pattern, which refers to the intrinsic and extrinsic characteristics of roles and relationships influencing resilience; situational pattern, which portrays resilience as a capacity for action and assessment in a stressful situation; and the philosophical pattern, which includes personal positive beliefs and reflection. Polk (1997) posited that individuals experience adversity as a force to change. And with enough 'chaos' in the experience, the patterns transform and evolve to a higher level of organisation and functioning. Furthermore, Polk (1997) also states that problem-solving is an essential strategy for survival.

In summary, to demonstrate resilience, individuals must first encounter adversity and successfully cope and adapt in a positive manner in order to develop resilience to future stress (DiCorcia \& Tronick, 2011; Polk, 1997). The following section will explore the relationship between, work stress, coping strategies and resilience.

\subsection{Resilience, Coping Strategies and Work Stress}

Work stress can be viewed as any negative, stressful or difficult situation of hardship that is encountered in the occupational setting (Jackson et al., 2007). In this fast paced society, organisations and individuals face risks at work brought by changes and uncertainties in the economy. Hence, building resilience will help ensure employees stay motivated, committed and maintain performance through periods of uncertainty and change (Maddi \& Khoshaba, 2005). Employers and employees alike have a responsibility to be as resilient as possible against the uncertainties of everyday working lives (Maddi \& Khosahaba, 2006; Spangler et al., 2012). It has been suggested that resilience buffers against the negative impacts of work stress, especially the inherently challenging working environments (Howard, 2008).

Several common themes similar to the four patterns of resilience (Polk, 1997) were identified when reviewing literature on resilience, for instance self-reliance and efficacy, positive outlook on things, close network of social relationships, intelligence and positive emotions etc. (Beardslee, 1989; Polk, 1997; Jackson et al., 2007; Mealer, Jones, \& Moss, 2012; Tugade \& Fredrickson, 2004). These themes seem to enhance the resilience factor in regulating stress and preventing negative health outcomes (Dolbier et al., 2009; Polk, 1997). When compared to coping resources that individuals draw upon to facilitate coping process, resilience factors seem to play a similar role. In a self-understanding study, Beardslee (1989) connected self-understanding, resilience and cognitive appraisal (part of coping process). His study posited that work situations will change over time and appraising stressful work situations allows the female employees to focus their energies and take appropriate action. There is then a connection between stressful life events and the importance of cognitive appraisal in managing the 
stressor. In the work context, the changing nature of the working environment over the long term and the need for the employee to alter her appraisal in response is emphasized by resilience (Beardslee, 1989). Furthermore, Beardslee's (1989) findings pointed out resilient individuals were those who engaged themselves in action. In other words, they acted on the problem.

To date, there seems to have a lack of findings measuring resilience in working mothers and females in general, even in Malaysia. As the roots of resilience are found in psychological aspects of coping and physiological aspects of stress, most research has been conducted in the areas of mental and social health (Kinman \& Grant, 2011; Wilks \& Spivy, 2010), nursing (Jackson et al., 2007; Mealer et al., 2012), and trauma (Scali et al., 2012). Overwhelmingly, the findings point to the importance of promoting positive ehavior, identifying and minimizing risks, cultivating the relationship of resilience with other factors, and developing intervention programmes that incorporate support network resources. Although there is a wealth of literature on this subject, there are gaps in the findings. Empirical studies have primarily focused on at risk females who are physically and mentally ill, abused, psychologically vulnerable and maladjusted, while little is known about females who are considered physically and mentally healthy. It will be interesting to include working mothers and female in resilience studies to observe the interplay between work stress and resilience, especially working mothers who play multiple roles.

Drawing from studies on nurses, whose occupational settings always contain elements of stressful, traumatic and difficult situations, building resilience in nurses is essential to assist them in dealing with work stress (Mealer et al., 2012; Tusaie \& Dyer, 2004). Giordano (1997) suggest that building personal resilience may be a means to cope with the stress nurses face at work. In nursing studies by Jackson et al. (2007) and Mealer et al. (2012), highly resilient nurses are identified to have psychological characteristics or personal resources such as optimism, positive social networks, cognitive flexibility, a set of active coping skills and more reflective. This set of characteristics and skills can be developed through therapy, training or self-development programmes which supports Muller's (2009) idea that resilience can be learned to protect against the negative effects of stress.

Alternatively, in a study on role of trauma exposure and anxiety disorders in adult women, Scali et al. (2012) found that women scoring high in the 10-Items Connor-Davidson Resilience Scale (CD-RISC-10) were less likely than women scoring low in the CD-RISC-10 to develop anxiety and mood disorders. They linked resilience and lifetime trauma exposure and found that the variables are influenced by the self-evaluation of resilience by the women faced with current stressful situations and the different perception of stress. They further commented that individuals with some history of lifetime low or moderate adversity are better adjusted with healthy well-being in recent adverse events than individuals with no history of adversity and high adversity. The concept concurs with the idea that resilience grows with successful process of coping in adversity and leads to a better psychological functioning and well-being (Scali et al., 2012; van Heugten, 2013). In the same way, resilience and successful coping in work stress are able to buffer against negative effects of stress and improve the working females' well-being.

\section{Conclusion}

Although there is still a lot to learn about how working females meet and adapt to stressful work situations, with the limited literature on work stress in Malaysian women, this review has attempted to recognise the building factors of resilience in the capacity of enhancing effective coping strategies to assist the working females to thrive and sustain satisfying careers in their work environment. Therefore programmes that focus on teaching resilience, that is, understanding and effectively coping with the stressful situation, are likely to reduce the risk of developing negative health effects for this population. Based on the literature, most stress and coping studies were found to focus on working mothers, working single mothers and non-working mothers. Research that studied the overall working female population did not separately compare working mothers and working single females (not married and no children). Even though it can be assumed through supporting studies on working mothers stress that they experience a higher level of work stress, a comparison study with working single females is warranted to further explore the differences in forms of coping strategies utilised and resilience level of both female groups. Similarly, since there is also a lack of findings on resilience among working single females and mothers, more research is needed to better understand the impact resilience has on both working groups.

\section{References}

Ahmad, A. (1996). Work-family conflict among married professional women in Malaysia. Journal of Social Psychology, 136(5), 663-665. http://dx.doi.org/10.1080/00224545.1996.9714054

Baltes, B., Zhdanova, L., \& Clark, M. (2011). Examining the relationships between personality, coping strategies, and work-family conflict. Journal of Business \& Psychology, 26(4), 517-530. 
http://dx.doi.org/10.1007/s10869-010-9207-0

Bartley, M., Schoon, I., Mitchell, R., \& Blane, D. (2010). Resilience as an asset for healthy development. In A. Morgan, M. Davies, \& E. Ziglio (Eds.), Health Assets in a Global Context (pp. 101-115). New York: Springer New York. http://dx.doi.org/10.1007/978-1-4419-5921-8_6

Beardslee, W. R. (1989). The role of self-understnading in resilient individuals. American Journal of Orthopsychiatry, 59(2), 266-278. http://dx.doi.org/10.1111/j.1939-0025.1989.tb01659.x

Bourne, L. E. Jr., \& Yaroush, R. A. (2003). Stress and cognition: A cognitive psychological perspective. (NASA Grant No. NAG2-1561). Boulder, Colorado: University of Colorado. Retrieved from http://humanfactors.arc.nasa.gov/eas/publications.html

Broussard, C. A., Joseph, A. L., \& Thompson, M. (2012). Stressors and coping strategies used by single mothers living in poverty. Affilia, 27(2), 190-204. http://dx.doi.org/10.1177/0886109912443884

Bynum, M. S., \& Brody, G. H. (2005). Coping behaviors, parenting, and perceptions of children's internalizing and externalizing problems in rural African American mothers. Family Relations, 54, 58-71. http://dx.doi.org/10.1111/j.0197-6664.2005.00006.x

Canam, C. J. (1986). Perceived stressors and coping responses of employed and non-employed career women with preschool children. Canadian Journal of Community Mental Health, 5(2), 49-59.

Carver, C., Scheier, M. F., \& Weintraub, J. K. (1989). Assessing coping strategies: A theoretically based approach. Journal of Personality and Social Psychology, 56, 267-283. http://dx.doi.org/10.1037/00223514.56.2.267

Chew, C. S. (2013, February 28). Expect changes in Malaysian demography. New Straits Times. Retrieved from http://www.nst.com.my

Chong, P. K. (2014, January 7). Malaysians seen curbing spending as living costs surge: Economy. Bloomberg. Retrieved from http://www.bloomberg.com/news/2014-01-07/malaysians-seen-curbing-spending-as-livingcosts-surge-economy.html

Coverman, S. (1989). Role overload, role conflict, and stress: Addressing consequences of multiple role demands. Social Forces, 67(4), 965-982. http://dx.doi.org/10.1093/sf/67.4.965

Day, A. L., \& Livingstone, H. A. (2001). Chronic and acute stressors among military personnel: Do coping styles buffer their negative impact on health? Journal of Occupational Health Psychology, 6, 348-360. http://dx.doi.org/10.1037/1076-8998.6.4.348

DiCorcia, J. A., \& Tronick, E. (2011). Quotidian resilience: Exploring mechanisms that drive resilience from a perspective of everyday stress and coping. Neuroscience \& Biobehavioral Reviews, 35(7), 1593-1602. http://dx.doi.org/10.1016/j.neubiorev.2011.04.008

Dolbier, C. L., Jaggars, S. S., \& Steinhardt, M. A. (2010). Stress-related growth: Pre-intervention correlates and change following a resilience intervention. Stress \& Health: Journal of the International Society for the Investigation of Stress, 26(2), 135-147. http://dx.doi.org/10.1002/smi.1275

Eisengart, S. P., Singer, L. T., Kirchner, H. L., Meeyoung, O. M., Fulton, S., Short, E., \& Minnes, S. (2006). Factor structure of coping: Two studies of mothers with high levels of life stress. Psychological Assessment, 18, 278-288. http://dx.doi.org/10.1037/1040-3590.18.3.278

Fleming, P., Baum, A., \& Singer, J. E. (1984). Towards an integrative approach to the study of stress. Journal of Personality and Social Psychology, 46, 939-949. http://dx.doi.org/10.1037/0022-3514.46.4.939

Gazzaniga, M. S., Heatherton, T. F., \& Halpern, D. F. (2010). Psychological Science (3rd ed.). New York: W.W.Norton \& Company.

George, L. G., Helson, R., \& John, O. P. (2011). The "CEO" of women's work lives: How big five conscientiousness, extraversion, and openness predict 50 years of work experiences in a changing sociocultural context. Journal of Personality \& Social Psychology, 10(4), 812-830. http://dx.doi.org/10.1037/a0024290

Giordano, B. (1997). Resilience: A survival tool for the nineties. Association of Perioperative Registered Nurses Journal, 65, 1032-1036. http://dx.doi.org/10.1016/S0001-2092(06)62942-6

Glanz, K., Rimer, B. K., \& Lewis, F. M. (2002). Health behavior and health education: Theory, research and practice. San Francisco: Wiley \& Sons. 
Harlin-Clifton, S. (2008). The effects of Stress management training on work-stress coping levels for working mothers. (Doctoral thesis). Available from ProQuest Dissertations and Theses database.

Holdings, N. V. N. (2011). Women of Tomorrow: A study of women around the world. Retrieved from http://se.nielsen.com/site/documents/WomenofTomorrowwhitepaperFINAL062611.pdf

Howard, F. (2008). Managing stress or enhancing wellbeing? Positive psychology's contributions to clinical supervision. Australian Psychologist, 43(2), 105-113. http://dx.doi.org/10.1080/00050060801978647

Jackson, D., Firtko, A., \& Edenborough, M. (2007). Personal resilience as a strategy for surviving and thriving in the face of workplace adversity: A literature review. Journal of Advanced Nursing, 60, 1-9. http://dx.doi.org/10.1111/j.1365-2648.2007.04412.x

Killien, M., \& Brown, M. A. (1987). Work and family roles of women: Sources of stress and coping strategies. Health Care for Women International, 8(2-3), 169-184. http://dx.doi.org/10.1080/07399338709515780

Kinman, G., \& Grant, L. (2011). Exploring stress resilience in trainee social workers: The role of emotional and social competencies. British Journal of Social Work, 41(2), 261-275. http://dx.doi.org/10.1093/bjsw/bcq088

Kitano, M., \& Lewis, R. (2005) Resilience and coping: Implications for gifted children and youth at risk. Roeper Review, 27, 200-205. http://dx.doi.org/10.1080/02783190509554319

Klainin, P. (2009). Stress and health outcomes: The mediating role of negative affectivity in female health care workers. International Journal of Stress Management, 16(1), 45-64. http://dx.doi.org/10.1037/a0013693

Kline, M., \& Snow, D. (1994). Effects of a worksite coping skills intervention on the stress, social support, and health outcomes of working mothers. Journal of Primary Prevention, 15(2), 105-121. http://dx.doi.org/10.1007/BF02197142

Kok, H. L. (1982). Age at first marriage in Peninsular Malaysia. Journal of Marriage and Family, 44(3), 785-798. http://dx.doi.org/10.2307/351600

Kushnir, T., \& Melamed, S. (2006). Domestic stress and well-being of employed women: Interplay between demands and decision control at home. Sex Roles: A Journal of Research, 54(9-10), 687-694. http://dx.doi.org/10.1007/s11199-006-9040-0

Lazarus, R. S., \& Folkman, S. (1984). Stress, Appraisal and Coping. New York, NY: Springer Publishing Company.

Leader, D. S. (1987). The well-being of working family women: Demands and rewards, social support and coping with interrole stress. (Doctoral thesis). Available from ProQuest Dissertations and Theses database. (Order No. 8802680).

Lim, L. L. (2009). Female labour-force participation. In United Nations (Eds.), Completing the fertility transition (pp. 203-221). United Nations Publication. Retrieved from http://www.un.org/esa/population/publications /completingfertility/RevisedLIMpaper

Lim, S., Cortina, L. M., \& Magley, V. J. (2008). Personal and workgroup incivility: Impact on work and health outcomes. Journal of Applied Psychology, 93(1), 95-107. http://dx.doi.org/10.1037/0021-9010.93.1.95

Maddi, S. R., \& Khoshaba, D. M. (2005). Resilience at Work: How to Succeed No Matter What Life Throws at You. New York, NY: AMACOM.

McLaughlin, M., Cormier, L. S., \& Cormier, W. H. (1988). Relation between coping strategies and distress, stress, and marital adjustment of multiple-role women. Journal of Counseling Psychology, 35(2), 187-193. http://dx.doi.org/10.1037/0022-0167.35.2.187

Mealer, M., Jones, J., \& Moss, M. (2012). A qualitative study of resilience and posttraumatic stress disorder in United States ICU nurses. Intensive Care Medicine, 38(9), 1445-1451. http://dx.doi.org/10.1007/s00134012-2600-6

Melchior, M., Caspi, A., Milne, B. J., Danese, A., Poulton, R., \& Moffitt, T. E. (2007). Work stress precipitates depression and anxiety in young, working women and men. Psychological Medicine, 37(8), 1119-1129. http://dx.doi.org/10.1017/S0033291707000414

Meleis, A. I., \& Stevens, P. E. (1992). Women in clerical jobs: Spousal role satisfaction, stress, and coping. Women \& Health, 18(1), 23-40. http://dx.doi.org/10.1300/J013v18n01_02

Michie, S. (2002). Causes and management of stress at work. Occupational and Environmental Medicine, 59, 67-72. http://dx.doi.org/10.1136/oem.59.1.67 
Ministry of Women, Family and Community Development. (2012). Statistics on women, family and community 2011, Malaysia. Retrieved from http://www.kpwkm.gov.my/documents/10156/40316aed-5eec-48729763-b22e7be8cfee

Mohd Mahudin, N. D. (2012). Transfer effects and permeable boundaries: An empirical study of the effects of commuting stress on employees' work and life. Southeast Asia Psychology Journal, 1, 1-9. Retrieved from http://www.cseap.edu.my/sapj

Monroe, D. A. B. (1991). Perceived stress and coping resources among single working mothers. (Doctoral thesis). Available from ProQuest Dissertations and Theses database. (Order No. 9237322).

Montpetit, M. A., Bergeman, C. S., Deboeck, P. R., Tiberio, S. S., \& Boker, S. M. (2010). Resilience-as-process: Negative affect, stress, and coupled dynamical systems. Psychology \& Aging, 25(3), 631-640. http://dx.doi.org/10.1037/a0019268

Muller, R. (2009). The importance of Resilience to Primary Care Practitioners: An Interactive Psycho-Social Model. The Australasian Medical Journal, 1(1), 1-15. http://dx.doi.org/10.4066/amj.2009.23

Nair, E. (2005, December). Women in the board room. Invited paper presented at 8th GOPIO (Global Organization of Persons of Indian Origin) International Convention, 17-18 December 2005, Furama City Centre, Singapore.

Nair, E. (2011). Urban career women and stress in Southeast Asia. Journal of Adult Development, 18(2), 62-65. http://dx.doi.org/10.1007/s10804-010-9115-6

National Institute for Occupational Health and Safety. (1999). Stress at work. (DHHS NIOSH Publication No. 99-101). Ohio, United States of America: Author.

Neill, J. T., \& Dias, K. L. (2001). Adventure education and resilience: The double-edged sword. Journal of Adventure Education \& Outdoor Learning, 1(2), 35-42. http://dx.doi.org/10.1080/14729670185200061

Noor, N. (1999). Roles and women's well-being: Some preliminary findings from Malaysia. Sex Roles, 41(3-4), 123-145. http://dx.doi.org/10.1023/A:1018846010541

Novaco, R. W., Kliewer, W., \& Broquet, A. (1991). Home environmental consequences of commute travel impedance. American Journal of Community Psychology, 19(6), 881-909. http://dx.doi.org/10.1007/ BF00937890

O'Bryan, A. (2008). Perceived stress, coping strategies, and role strain of working mothers enrolled in a Master's program (Doctoral thesis). Available from ProQuest Dissertations and Theses database. (UMI No.: 3325345)

O'Neill, C. P., \& Zeichner, A. (1985). Working women: A study of relationships between stress, coping and health. Journal of Psychosomatic Obstetrics \& Gynecology, 4(2), 105-116. http://dx.doi.org/10.3109/ 01674828509085266

Pearlin, L. I. (1989). The sociological study of stress. Journal of Helath and Social Behavior, 30(3), 241-256. Retrieved from https://campus.fsu.edu/bbcswebdav/institution/academic/social_sciences/sociology/ Reading\%20Lists/Mental\%20Health\%20Readings/Pearlin-HealthSocial-1989.pdf; http://dx.doi.org/10.2307/2136956

Polk, L. V. (1997). Toward a middle-range theory of resilience. Advances in Nursing Science, 19(3), 1-13. http://dx.doi.org/10.1097/00012272-199703000-00002

Raak, R., \& Wahren, L. K. (2005). Headache and coping in a female working population. Scandinavian Journal of Caring Sciences, 19(4), 325-329. http://dx.doi.org/10.1111/j.1471-6712.2005.00347.x

Ritchie, J. (1982). Child-rearing practices and attitudes of working and full-time mothers. Women's Studies International Forum, 5(5), 419-425. http://dx.doi.org/10.1016/0277-5395(82)90004-8

Rutter, M. (2012). Resilience as a dynamic concept. Development and Psychopathology, 24(2), 335-344. http://dx.doi.org/10.1017/S0954579412000028

Sandmark, H., \& Renstig, M. (2010). Understanding long-term sick leave in female white-collar workers with burnout and stress-related diagnoses: A qualitative study. BMC Public Health, 10(1), 1-12. http://dx.doi.org/10.1186/1471-2458-10-210

Scali, J., Gandubert, C., Ritchie, K., Soulier, M., Ancelin, M., \& Chaudieu, I. (2012). Measuring resilience in adult women using the 10-Items Connor-Davidson Resilience Scale (CD-RISC). Role of trauma exposure 
and anxiety disorders. PLoS ONE, 7(6), 1-7. http://dx.doi.org/10.1371/journal.pone.0039879

Schetter, C. D., \& Dolbier, C. (2011). Resilience in the context of chronic stress and health in adults. Social and Personality Psychology Compass, 5(9), 634-652. http://dx.doi.org/10.1111/j.1751-9004.2011.00379.x

Shek, D. T. L. (1989). Reliance on self or seeking help from others: Gender differences in the locus of coping in Chinese working parents. The Journal of Psychology, 126(6), 671-678. http://dx.doi.org/10.1080/00223980. 1992.10543397

Snow, D. L., Swan, S. C., Raghavan, C., Connell, C. M., \& Klein, I. (2003). The relationship of work stressors, coping and social support to psychological symptoms among female secretarial employees. Work \& Stress, 17(3), 241-263. http://dx.doi.org/10.1080/02678370310001625630

Spangler, N. W., Koesten, J., Fox, M. H., \& Radel, J. (2012). Employer perceptions of stress and resilience intervention. Journal of Occupational \& Environmental Medicine, 54(11), 1421-1429. http://dx.doi.org/ 10.1097/JOM.0b013e3182619038

Street, A. E., Gradus, A. L., Stafford, J., \& Kelly, K. (2007). Gender differences in experiences of sexual harassment: Data from a male-dominated environment. Journal of Consulting and Clinical Psychology, 75(3), 464-474. http://dx.doi.org/10.1037/0022-006X.75.3.464

Talent Corp, \& ACCA Malaysia. (2012). TalentCorp-ACCA Malaysia report on retaining women in the workforce. Kuala Lumpur, Malaysia: Author.

The World Bank. (2013). Labor participation rate, female (\% of female population ages 15+). Retrieved March 12, 2013, from http://data.worldbank.org/indicator/SL.TLF.CACT.FE.ZS

Tugade, M. M., \& Fredrickson, B. L. (2004). Resilient individuals use positive emotions to bounce back from negative emotional experiences. Journal of Personality \& Social Psychology, 86(2), 320-333. http://dx.doi.org/10.1037/0022-3514.86.2.320

Tusaie, K., \& Dyer, J. (2004). Resilience: A historical review of the construct. Holistic Nursing Practice, 18, 3-10. http://dx.doi.org/10.1097/00004650-200401000-00002

van Heugten, K. (2013). Resilience as an underexplored outcome of workplace bullying. Qualitative Health Research, 23(3), 291-301. http://dx.doi.org/10.1177/1049732312468251

von Elm, B., \& Hirschm, C. (1979). Age at first marriage in Peninsular Malaysia. Journal of Marriage and the Family, 41, 877-891. Retrieved from http://faculty.washington.edu/charles/pubs/1979-AgeatFirstMarriagein PeninsularMalaysia.pdf; http://dx.doi.org/10.2307/351487

Wagnild, G. M., \& Young, H. M. (1993). Development and psychometric evaluation of the Resilience Scale. Journal of Nursing Measurement, 1(2), 165-179.

Wanamaker, N. J., \& Bird, G. W. (1990). Coping with stress in dual career marriages. International Journal of Sociology of the Family, 20(2), 199-211.

Wee, Y. G., Ibrahim, M. D. B., \& Poerwowidagdo, S. J. (n. d.). Occupational stress: A survey of women managers in Malaysia, 1-18. Retrieved from http://www.wbiconpro.com/451-Wee.pdf

Wener, R., \& Evans, G. W. (2004). The impact of mode and mode transfer on commuter stress: The Montclair Connection. Final Report. No. FHWA-NJ-2004-005. Retrieved from http://www.utrc2.org/research/assets 174/commuterstress2-report1.pdf

Wilks, S. E., \& Spivey, C. A. (2009). Resilience in undergraduate social work students: Social support and adjustment to academic stress. Social Work Education, 29(3), 276-288. http://dx.doi.org/10.1080/ 02615470902912243

\section{Copyrights}

Copyright for this article is retained by the author(s), with first publication rights granted to the journal.

This is an open-access article distributed under the terms and conditions of the Creative Commons Attribution license (http://creativecommons.org/licenses/by/3.0/). 